\section{TRABALHO PEDAGÓGICO, TRABALHO DOS PROFESSORES E TRABALHO DOCENTE: MOVIMENTOS DE SENTIDOS NAS ABORDAGENS SOBRE EDUCAÇÃO FÍSICA ESCOLAR}

\author{
PEDAGOGICAL WORK, TEACHERS' WORK AND TEACHING WORK: \\ MOVEMENTS OF MEANINGS IN APPROACHES ON SCHOOL \\ PHYSICAL EDUCATION
}

\author{
TRABAJO PEDAGOGGICO, TRABAJO DE LOS PROFESORES Y \\ TRABAJO DOCENTE: MOVIMIENTOS DE SENTIDOS EN LOS \\ ENFOQUES SOBRE EDUCACIÓN FÍSICA ESCOLAR
}

\section{Liliana Soares Ferreira*, Ana Paula Cristino Zimmerman**, Vicente Cabrera Calheiros*}

Palavras chave: Trabalho. Docentes. Ensino.

Keywords: Work.

Faculty. Teaching.

Palabras clave: Trabajo.

Docentes.

Enseñanza.
Resumo: Relata-se análise de movimento de sentidos das categorias trabalho pedagógico, trabalho dos professores e trabalho docente, em artigos de dois periódicos da área de Educação Física, com atenção para como os autores abordam esses temas em artigos publicados entre os anos de 2008 e 2018. Nos textos lidos, constatou-se: a) os textos não distinguem as categorias em análise, transformando-as em sinônimos; b) "Trabalho docente" é a expressão mais aplicada como sinônimo para referir-se ao trabalho dos professores; c) Organização do trabalho pedagógico é uma expressão aplicada, objetivando sentido mais ampliado que trabalho pedagógico.

Abstract: This paper describes movements of meanings in the categories trabalho pedagógico (pedagogical work), trabalho dos professores (teachers' work) and trabalho docente (teaching work) in two Physical Education journals, focused on how those topics are addressed in articles published in 2008-2018. In the texts, it was found that: a) the articles do not distinguish those categories and use them as synonyms; b) "Teaching work" is used most often as a synonymous to refer to teachers' work; c) Organization of pedagogical work is used in a broader sense than pedagogical work.

Resumen: Se relata análisis de movimiento de sentidos de las categorías "trabajo pedagógico, trabajo de los profesores y trabajo docente", en artículos de dos periódicos del área de Educación Física, con atención a cómo los autores abordan estos temas en artículos publicados entre los años 2008 y 2018. En los textos leídos, se constató: a) los textos no distinguen las categorías en análisis, transformándolas en sinónimos; b) "Trabajo docente" es la expresión más aplicada como sinónimo para referirse al trabajo de los profesores; c) Organización del trabajo pedagógico es una expresión aplicada objetivando sentido más ampliado que trabajo pedagógico.
*Universidade Federal de Santa Maria. Santa Maria, RS, Brasil. E-mail:

anaililferreira@yahoo.com.br; vicocalheiros@gmail.com.

${ }^{* *}$ Rede Municipal de Santa Maria. Santa Maria, RS, Brasil. E-mail: anacristino@hotmail.com

Recebido em: 09-01-2020 Aprovado em: 07-05-2020 Publicado em: 11-06-2020 


\section{INTRODUÇÃO}

Nos últimos anos, estamos nos dedicando a estudos para aprofundamento de categorias que nos permitam compreender e descrever o trabalho dos professores de Educação Física na escola. Neste artigo, sistematizamos um desses estudos, cujo objetivo foi investigar os movimentos de sentidos sobre as categorias trabalho pedagógico, trabalho dos professores e trabalho docente em dois periódicos com Qualis ${ }^{1}$, na área de Educação Física: a Movimento e a Motriz, em suas edições entre os anos de 2008 e 2018. Entende-se por "Análise de Movimentos de Sentidos", uma investigação, objetivando descrever abordagens sobre um tema, a partir da análise de um corpus específico. Nesse processo, estudam-se "[...] os sentidos em suas variações, incidências, repetições, faltas e exageros, etc, ou seja, em seus movimentos" (FERREIRA; BRAIDO; DE TONI, 2020, p. 150). É, portanto, "um estudo de linguagem", elaborado no grupo de pesquisa do qual se participa ${ }^{2}$, que pressupõe "[...] organização, reorganização, comparação, cotejamento e sistematização dos discursos" (FERREIRA; BRAIDO; DE TONI, 2020, p. 150). Nessa perspectiva, a análise "[...] alia interpretação, análise, compreensão, objetivando adentrar nos discursos, evidenciando sentidos que se confirmarão ou não, quando cotejados com outros" (FERREIRA; BRAIDO; DE TONI, 2020, p. 150). O rigor na aplicação da técnica exige atenção à pergunta que deu origem ao estudo, de modo minucioso, com a elaboração de instrumentos de análise, um conjunto de tabelas, figuras, gráficos, etc, conforme o caso. Com base nesses instrumentos, a leitura aprofunda-se e "Partese, então, para sínteses, ou seja, agrupamento dos sentidos em suas semelhanças, com o intuito de ir recompondo o texto, agora significado" (FERREIRA; BRAIDO; DE TONI, 2020, p. 150). Deriva, então, a sistematização, "[...] momento de se escrever sobre as sínteses, ou seja, elaborar a argumentação que, ao fim e ao cabo, é um outro sentido sobre o lido" (FERREIRA; BRAIDO; DE TONI, 2020, p. 150).

No caso do estudo ora sistematizado, objetivou-se entender como os autores dos artigos abordam esses temas, quais obras e autores referendam seus argumentos e proposições teóricas. Partiu-se do suposto que, dada a abrangência, divulgação e relevância desses periódicos, poder-se-ia compreender os sentidos, as abordagens e encontrar indicativos para a continuidade de nossos estudos. Vale dizer, pretendeuse estabelecer um diálogo propositivo e buscar o aprofundamento deste debate, por entendermos que são categorias com sentidos distintos, sendo, por isso, necessário esclarecê-los.

A seleção dos artigos analisados nos dois periódicos foi organizada com base nos seguintes critérios: a) conterem no título ou no resumo pelo menos uma das categorias de análise nessa investigação; b) terem sido publicados no período de análise, dez anos. A análise, desse modo, configurou-se em um estudo, tendo como referência teórica e metodológica, a Análise de Movimentos de Sentidos - AMS. Para

\footnotetext{
1 Qualis é o conjunto de procedimentos utilizados pela Capes (Coordenação de Aperfeiçoamento de Pessoal de Nível Superior) para estratificação da qualidade da produção intelectual dos programas de pós-graduação. Essa produção é enquadrada em estratos indicativos de qualidade, sendo o A1 e A2 os mais elevados. Qualis Periódicos. Disponível em: https://sucupira.capes.gov.br/sucupira/public/consultas/coleta/veiculoPublicacaoQualis/ listaConsultaGeralPeriodicos.jsf . Acesso em: 23 maio 2020.

2 Está-se referindo ao Kairós - Grupo de Estudos e Pesquisas sobre Trabalho, Educação e Políticas Públicas, ligado à Universidade Federal de Santa Maria, Rio Grande do Sul.
} 
a produção de dados, elaboraram-se categorias prévias orientadoras no processo de análise documental dos artigos selecionados.

A leitura inicial dos periódicos permitiu encontrar treze textos (sete artigos originais e seis ensaios) na revista Movimento e seis textos (três artigos originais, um ensaio, um artigo de atualização ou divulgação e um artigo de revisão) na revista Motriz, entre o período selecionado. Em três textos da revista Movimento não foram encontradas as categorias de análise no corpo do texto, indicando que, apesar de o título induzir a pensar que o texto abordaria essas categorias, isso não aconteceu. Tratam-se de dois artigos originais e um ensaio ${ }^{3}$. Em outro ensaio ${ }^{4}$, os autores abordam a temática do trabalho pedagógico, entretanto, não explicitam seu entendimento a respeito, embora apontem as referências que embasam seu ponto de vista. O mesmo acontece com outro ensaio, que analisa o trabalho docente ${ }^{5}$. Portanto, para a análise proposta neste artigo, estes textos foram descartados. Analisamos, assim, seis textos da revista Movimento e um na revista Motriz, uma vez que, em quatro artigos desta revista, 2 artigos originais, 1 ensaio e 1 artigo de atualização ou divulgação, não foram encontradas as categorias de análise ${ }^{6}$.

Uma primeira descrição dos artigos analisados inclui destacar o quanto, por serem produzidos por autores de diversas Instituições de Ensino Superior, representam as abordagens sobre trabalho e Educação Física no país, além do destaque aos objetivos que orientaram a produção:

- Os autores dos textos da revista Movimento representam universidades das Regiões Centro-oeste, Sudeste, Sul e Distrito Federal: Universidade Federal de Viçosa, Universidade Gama Filho, Universidade Federal de Santa Catarina, Faculdade da Serra Gaúcha, Universidade Federal de Pelotas, Universidade Federal de Goiás, Universidade Nacional de Brasília, Universidade Federal do Rio

\footnotetext{
3 Referimo-nos aos seguintes textos:

ANDRADE, Rafael Júnio; PEREIRA, Eveline Torres; BOTELHO, Maria Izabel; SILVA, Sílvio Ricardo. Trabalho destruído e funcionalização do lazer: possíveis relações em tempos de alta modernidade. Movimento, v. 14, n. 01, 2008. Disponível em: http://seer.ufrgs.br/Movimento/article/view/3763. Acesso em: 20 ago. 2019.

VOTRE, Sebastião Josué; VIGNE, Joana Angélica; LACERDA, Yara. Mulheres da rocinha: relações entre corpo, identidade e trabalho. Movimento, v. 14, n. 03, 2008. Disponível em: http://seer.ufrgs.br/Movimento/article/ view/2550. Acesso em: 20 ago. 2019.

BOSSLE, Fabiano; MOLINA NETO, Vicente. Leituras para (Re)Pensar o Trabalho Coletivo dos Professores de Educação Física. Movimento, v. 15, n. 03, 2009. Disponível em: http://seer.ufrgs.br/Movimento/article/view/6877. Acesso em: 20 ago. 2019.

4 CALHEIROS, Vicente Cabrera; SOUZA, Maristela da Silva. A educação do MST e a relação com o Estado: análise a partir da avaliação em Educação Física na Escola Nova Sociedade. Movimento, v. 21, n. 2, abr./jun. 2015. DOI: https://doi.org/10.22456/1982-8918.47507

5 NASCIMENTO, Raquel; MARTINS, Alessandra; BOTH, Jorge; FARIAS, Gelcemar; GUIMARÃES, Juliana; FOLLE. Alexandra. Satisfação no trabalho de docentes de Educação Física: uma revisão sistemática. Movimento, $\underline{\mathrm{v} .} 25$, jan./ dez. 2019. https://doi.org/10.22456/1982-8918.82573

6 Os textos não analisados foram:

VERENGER, Rita de Cássia; CAMPANELLI, José Renato; KALLAS, Daniele; FREIRE, Elisabete; COSTA, Ferdinand. Mercado de trabalho em EF: o significado da intervenção profissional em academias de ginástica. Motriz, v. 14, n. 04, 2008. Disponível em: http://www.periodicos.rc.biblioteca.unesp.br/index.php/motriz/article/ view/2133. Acesso em: 20 ago. de 2019.

PRONI, Marcelo. Universidade, profissão Educação Física e o mercado de trabalho. Motriz, v. 16, n. $03,2010$. Disponível em:http://dx.doi.org/10.5016/1980-6574.2010v16n3p788. Acesso em: 20 ago. 2013.

NUNES, Marcello; VOTRE, Sebastião; SANTOS, Wagner dos. O profissional em Educação Física no Brasil: desafios e perspectivas no mundo do trabalho. Motriz, v. 18, n. 02, 2012. Disponível em: http://www.periodicos. rc.biblioteca.unesp.br/index.php/motriz/article/view/4975. Acesso em: 20 ago. 2019.

TANI, Go. Preparação profissional em Educação Física: mudando mercado de trabalho e competência. Motriz, v. 19, n. 03, 2013. Disponível em: http://www.periodicos.rc.biblioteca.unesp.br/index.php/motriz/article/view/7367. Acesso em : 20 ago. 2019.
} 
Grande do Sul, Universidade Comunitária da Região de Chapecó, Universidade Regional do Noroeste do Estado do Rio Grande do Sul, Universidade Federal de Santa Maria. Os autores dos textos da revista Motriz representam universidades das Regiões Sudeste e Sul: Universidade Mackenzie, Universidade Federal de Santa Catarina, Universidade Estadual de Maringá, Universidade Estadual de Campinas, Universidade Federal do Espírito Santo, Universidade de São Paulo, Universidade Federal do Rio Grande do Norte. Na revista Movimento, dois autores têm mais de um texto: Vicente Molina Neto, professor da Universidade Federal do Rio Grande do Sul, contribuiu com três textos e Fabiano Bossle, da mesma Universidade, contribuiu com dois textos. Os demais autores apresentam apenas um texto.

- Os artigos têm como objetivo: I) Abordar os principais problemas enfrentados no trabalho docente, mais especificamente dos professores de Educação Física da Educação Básica; II) Analisar as características do trabalho do professor de Educação Física e a inserção da disciplina na organização do trabalho pedagógico no formato ciclado de ensino. III) Avaliar as implicações dos processos de gestão e tendências de inovação inerentes ao desenvolvimento da "Indústria do Fitness" para o trabalho do professor de Educação Física. IV) Refletir acerca das aproximações entre Educação Física (EF) e hermenêutica, como possibilidade de uma orientação para o trabalho docente nesse campo; V) Apresentar as ações e os resultados de um projeto de formação continuada desenvolvido entre os professores de Educação Física da região da Quarta Colônia e do CEFD/UFSM como também as implicações das políticas governamentais do Estado do Rio Grande do Sul neste processo; VI) Identificar quais mudanças sociais influenciam o trabalho docente do professorado de Educação Física na escola e, assim, compreender como esses professores experimentam tais mudanças, produzindo respostas e enfrentamentos às demandas sociais, culturais e educacionais na comunidade escolar em que atuam; VII) Sistematizar aproximações entre a praxiologia motriz e a pedagogia histórico-crítica, por meio do entendimento de que esta pedagogia embasa a concepção pedagógica Crítico Superadora; VIII) Analisar a categoria avaliação, entendida como elemento modular do trabalho pedagógico, a partir de uma escola em área de reforma agrária; IX) Discutir a respeito de alguns elementos condicionantes e restrições ao trabalho docente relacionados ao desenvolvimento da prática pedagógica na Educação Física; X) Discutir sobre o trabalho docente dos professores de Educação Física no Ensino Fundamental. Em linhas gerais, observa-se que os artigos não se dedicam a esclarecer as categorias, mas, abordálas em relação aos temas que descrevem. Mesmo assim, entendemos que são produções relevantes para que se possa compreender como são abordadas essas categorias na literatura da área da Educação Física.

\section{UMA DESCRIÇÃO DAS CATEGORIAS TRABALHO DOCENTE E TRABALHO PEDAGÓGICO}

Em muitas oportunidades, observou-se que trabalho pedagógico, trabalho dos professores e trabalho docente são aplicados como se fossem sinônimos. 
Entendemos que são categorias que explicitam sentidos diferentes, os quais passaremos a apresentar a seguir, a iniciar por uma descrição de trabalho docente. Após, abordaremos trabalho dos professores e finalizaremos com uma abordagem sobre trabalho pedagógico.

Por trabalho docente, expressão que não temos priorizado em nossos escritos, entende-se um trabalho genericamente descrito como docência. Consideramos complicado o sentido de docência e concordamos com a crítica apresentada por Frizzo (2008) que, do ponto de vista etimológico, o sentido de docência refere-se ao "[...] exercício do magistério ou relativo a quem ensina (docente), trazendo consigo uma perspectiva dos processos de apropriação do conhecimento baseada na concepção bancária de educação" (FRIZZO, 2008, p. 9). Como se sabe, a perspectiva bancária de educação, com base em Paulo Freire (1987), apresenta uma metáfora entre a educação escolar e uma operação monetária em um banco, prevendo o depósito, o investimento e o saque de conhecimentos, tendo como base, assim, uma perspectiva tradicional de educação. Nessa situação, parece haver um agente passivo, o docente, que pratica a docência, termo que, de imediato, não remete ao protagonismo no trabalho. Com base ainda no mesmo autor, reitera-se que tampouco a expressão "trabalho docente" revela de modo amplo o trabalho dos professores, visto que este compreende não existir docência sem discência, pelo fato de que ambas se explicam e seus sujeitos não se reduzem à condição de objeto um do outro. "Quem ensina aprende ao ensinar e quem aprende ensina ao aprender" (FREIRE, 2002, p. 25). Nesta perspectiva, "trabalho docente" é aplicada para "[...] designar a ação desenvolvida por professores e alunos na aquisição de conhecimento sistematizado" (FRIZZO, 2008, p. 9), conferindo um sentido restritivo na medida em que faz referência ao trabalho do professor, não incorporando o trabalho do estudante envolvido na ação pedagógica. Encontramos em um dos textos analisados uma citação que se aproxima:

\footnotetext{
Os argumentos dos colaboradores nos permitiram entender que o trabalho docente - ou poderíamos dizer num trocadilho (dor)sente - tem absorvido e sentido o efeito de uma sociedade diversa, globalizada, acelerada, que idealizava a educação como salvadora da humanidade e ainda não encontrou respostas satisfatórias ou confortáveis para dar conta disso. (WITTIZORECKI; MOLINA NETO; BOSSLE, 2012, p. 166)
}

Já trabalho pedagógico é uma categoria mais ampla, transcendendo a categoria trabalho docente, pois estabelece uma relação entre professor, estudante e as relações de trabalho no modo de produção capitalista. De acordo com Villas Boas (1993), o trabalho pedagógico é determinado pela sociedade, podendo reproduzir sua lógica, da mesma forma que trabalhar para sua superação. Compreende-se, então, que este trabalho apresenta as bases de sustentação das mediações estabelecidas entre os sujeitos que compõem o universo escolar, sendo estas contraditórias e conflitantes, possuindo em contrapartida, determinadas regularidades (MACHADO, 2003). Ao estabelecer esta relação entre a escola e as relações de produção e reprodução capitalistas, estando articulado ao processo de trabalho capitalista, tem sua finalidade no "[...] disciplinamento para a vida social produtiva, em conformidade com as especificidades que os processos de produção, em decorrência do desenvolvimento das forças produtivas, vão assumindo" (FRIZZO, 2008, p. 11). 
Ao inserir-se no processo de trabalho capitalista, o trabalho pedagógico torna-se uma prática social que "atua na configuração da existência humana individual e grupal para realizar nos sujeitos humanos as características de seres humanos" (LIBÂNEO, 1998, p. 22) e, por encontrar-se em uma sociedade dividida em classes sociais, com marcadas relações sociais de exploração, desempenhará as funções demandadas pelo projeto hegemônico, capitalista. Neste sentido pode-se afirmar, de acordo com Kuenzer (2002, p. 82), que a "[...] finalidade do trabalho pedagógico, articulado ao processo de trabalho capitalista, é o disciplinamento para a vida social e produtiva, em conformidade com as especificidades que os processos de produção [...] vão assumindo".

Compreendemos que o trabalho dos professores é sempre trabalho pedagógico, entendido como:

[...] o trabalho dos professores na escola e, portanto, práxis [...]. Tal trabalho foi descrito, a princípio, como sendo a aula e, nela, a produção do conhecimento dos professores e dos estudantes. Obviamente, essa é a primeira e principal instância do trabalho dos professores, pois a realização da aula implica envolvimento e participação política em reuniões, planejamentos, ações com a comunidade escolar, além de intenso imbricamento, comprometimento e responsabilidade com o projeto pedagógico institucional. Trata-se, portanto, de um movimento dialético entre o individual e o coletivo: entre o que os professores produzem, seu projeto pedagógico individual, e o que a escola, comunidade articulada, estabeleceu em seu projeto pedagógico institucional (RIBAS; FERREIRA, 2012, p. 03).

Assim, se há alguma possibilidade de sinônimos, proporíamos que trabalho pedagógico e trabalho dos professores, no sentido de que este é aquele, podem se substituir, desde que esclarecidas as referências. Entretanto, cabe descrever com mais vagar a categoria "trabalho dos professores". É o que faremos na seção seguinte.

\subsection{O TRABALHO DOS PROFESSORES}

Inicia-se a discussão sobre o trabalho dos professores, entendendo-o como possibilidade de encontrarem-se alternativas e possibilidades capazes de tornar a escola uma instituição mais coerente, ágil e produtiva. Do mesmo modo, entendemos ser necessária muita perspicácia para não se acabar sugerindo ser o trabalho dos professores um campo resultante de embates teóricos, normalmente estrangeiros, tampouco resultante de eventos ocorridos sempre em instâncias superiores, fora do alcance dos professores que, nessa descrição, parecem ser mantidos em níveis sociais aparentemente tão aquém dos contextos onde se produzem as políticas públicas, que não são sequer afetados por elas. Nestas duas sugestões, implicitamente, afirma-se que os professores trabalham em contextos tão afastados do social, a ponto de se manteremalheios a ele. Processo contrário ainda são as interpretações individualizadas e descoladas do social do trabalho dos professores apresentadas e utilizadas como explicações do coletivo. Obviamente, excluir tais abordagens é ignorá-las como os fundamentos sobre os quais as produções acontecem. È necessário considerar, como tem alertado Shiroma (2003), não se desconhecer um conjunto de processos políticos cotidianos que contribuem para a desintelectualização dos professores. A autora alerta que há um afastamento e sobreposição da prática em relação à teoria, intensificada nos últimos tempos, promovendo um distanciamento entre os estudos 
necessários ao trabalho e a repetição de práticas, nem sempre articuladas entre si, no cotidiano da escola. Assim, as abordagens que apresentamos acerca do trabalho dos professores têm privilegiado algumas crenças que Ihes dão suporte: a crença nos profissionais e em suas condições de transformar o real, sobretudo o entorno, por meio da práxis pedagógica ${ }^{7}$; por decorrência, a crença nos sujeitos como potencialmente dotados de saberes com os quais encaminham, na escola, a produção do conhecimento; a crença na produção do conhecimento, entendida como apropriação do que não se sabia, e agora se sabe; a crença na linguagem como possibilitadora da produção do conhecimento; a crença na escola como uma instituição que pode se revisitar e ainda ser um espaço-tempo de produção humana e pedagógica; a crença na aula como evento que reúne sujeitos em torno de um objetivo comum: conhecer e conhecer-se. Do mesmo modo, para falar-se em professor, como profissional, precisa-se considerar várias dimensões: a de trabalhador que percebe um salário e está incluso em um grupo de trabalhadores; a de um pensador incluso em diferentes movimentos sociais; a de cidadão e sujeito político, participante de grupos sociais e afeto a um Estado democrático. Os professores integram um grupo de trabalhadores com as mesmas condições, pertences a classe que vende a sua força de trabalho, conforme postula a compreensão marxiana (MARX, 2013). Em uma concepção atual de professor, de professora, adequada aos tempos atuais, busca-se propiciar processos educativos continuados e permanentes ao profissional da docência de modo que ele possa se tornar sujeito de sua práxis pedagógica, superando as condições de sua classe. Paralelamente, há um processo de produção muito bem estruturado que impede haver uma efetiva interação social; o fato de os professores terem como interlocutores os estudantes, seres semelhantes e com livre arbítrio (pelo menos, pró-forma) determina uma produção diferenciada.

Hargreaves (1998) caracteriza os tempos do trabalho dos professores, posto que reiteradamente encontram-se alusões ao tempo ou à falta dele nos discursos destes profissionais: a) o tempo técnico-racional; b) o tempo micropolítico; c) o tempo fenomenológico; d) o tempo sociopolítico. Enquanto os demais se referem ao tempo que controla, organiza, estipula as características do trabalho e da profissão dos professores, regulando-os em suas iniciativas, o tempo fenomenológico diz respeito ao tempo de cada ser em sua subjetividade e em sua historicidade. Esta abordagem é interessante para que se possa melhor entender e analisar como se organizam as condições de trabalho dos professores, sendo estas tão diferentes entre si frente a dimensão territorial brasileira e de sua estrutura educacional. Entretanto, de modo algum, podem ser sobrepostas ao trabalho em si, quando se procura analisar como se produz o trabalho dos professores na escola, ou seja, o tempo deve ser analisado de modo a articular suas distintas manifestações, conforme pontua Hargreaves (1998).

No caso dos profissionais da educação, por exemplo, a análise de seu trabalho precisa ter sempre como referência básica a aula assumida, não por professores

7 “[...] "a práxis pedagógica é a essência do trabalho profissional dos professores e, nessa perspectiva, tornase científica, por isso, metódica, sistemática, hermeneuticamente elaborada e teoricamente sustentada" (RIBAS; FERREIRA, 2014, p. 10). E, ainda, toda práxis pedagógica é social, porque "[...] socialmente elaborada e organizada conforme intencionalidades, conhecimentos" (FERREIRA, 2008, p.184). E Ribas e Ferreira ainda acrescentam: "Então, uma das incoerências ao se abordar o trabalho dos professores, é apresentá-lo como prática, quando exige uma leitura do real, uma proposição, uma validação da proposta e, ao longo do processo, uma avaliação. Portanto, é uma práxis, uma ação singular, responsável e produtiva em relação ao conhecimento. Se tratado como prática, é minimizado em sua potencialidade e reduzem-se as implicações do trabalhador com sua produção,diminuindo as implicações políticas desse trabalho" (RIBAS; FERREIRA, 2014, p. 12). 
isolados, mas por uma equipe dedicada ao trabalho solidário, em que devem se articular a reflexão em grupos e o estudo em tempos programados, para que se faça mais integrada, mais adequada às particularidades de cada turma de alunos e mais qualificada em termos de práticas consequentes e da compreensão teórica (MARQUES, 2001). E mais: trabalhar como professor implica a aprendizagem de uma profissão, caracterizada por saberes muito diversos, que vão do humano e relacional ao cognitivo e prático.

Nessa perspectiva, nossa escolha é descrever o trabalho dos professores como pedagógico, ou seja, como práxis pedagógica, entendendo que:

\begin{abstract}
As limitações e fundamentos do conhecimento ocorrem, pois, em e pela prática, que marca seus objetos de estudo, seus fins, e ademais, é o critério empírico da verdade. A práxis opera como fundamento porque somente se conhece o mundo por meio de sua atividade transformadora, a verdade ou falsidade de um pensamento funda-se na esfera humana ativa. Logo, a práxis exclui o materialismo ingênuo segundo o qual sujeito e objeto encontram-se em relação de exterioridade, e o idealismo que ignora os condicionamentos sociais da ação e reação para centrar-se no sujeito como ser isolado, autônomo e não-social (FRIZZO, 2008, p. 12).
\end{abstract}

Práxis, então, por ser um investimento na transformação necessária que o trabalho produz. Pedagógica porque considera tudo que "está implicado na ação de educar, mesmo que ainda não referendado pela Pedagogia, ou seja, no âmbito do senso comum" (RIBAS; FERREIRA, 2012, p. 10). Porém, há uma distinção do pedagógico sempre que estiver inserido na escola, pois, nesse caso, estará:

[...] regulamentado, normatizado, além de incidirem sobre ele, determinadas relações de poderes, próprias daquele espaço e daquele tempo, culturalmente elaborados. Essas relações se evidenciam cotidianamente, na escola, ou em qualquer espaço onde se evidenciem relações pedagógicas. Em alguns casos, são naturalizadas pelo grupo e não estão prescritas em nenhum documento. Sua repetição as naturaliza. São formas a partir das quais os sujeitos intercambiam saberes, culturas, historicidades (RIBAS; FERREIRA, 2012, p. 10)

Então, nenhuma práxis pode ser entendida senão como social, tendo em vista que o social é seu pressuposto, seu alicerce: "A própria práxis é pedagógica, porque interativa, porque põe em interação os sujeitos e, estes, ao interagirem, desde o nível inicial, já estão em interlocução de saberes"”" (RIBAS; FERREIRA, 2014, p. 10).

A práxis pedagógica é uma categoria que tem se sistematizado no Kairós - Grupo de Estudos e Pesquisas sobre trabalho, educação e políticas públicas, e no caminho que tem trilhado para sua constituição, evidencia-se como trabalho desenvolvido pelos pesquisadores, na condição de sujeitos que, juntos, transformam a si próprio e aos outros, tendo como centralidade a pesquisa. Essa natureza da práxis requer que o trabalho que se desenvolve na escola, entendido como pedagógico, se concretize simultaneamente à produção de sujeitos que se constituem nos âmbitos social e histórico. Sanchez Vázquez (2011) em um estudo aprofundado sobre a práxis, ao abordar no contexto do tema, os "homens, sujeitos da história", reforça

8 Expressão utilizada por Marques (1996) para explicar que a prática da linguagem é sempre interação, pressupõe que os sujeitos estejam envolvidos em uma situação dialógica, uma relação eu-tu: "Interlocução que não é simples amálgama de saberes prévios, o trespasse de uns nos outros; mas é aprender contra o previamente aprendido, negação do que já se sabe na constituição do novo saber, de saberes outros" (MARQUES, 1996, p. 14). 
a importância das relações estabelecidas para a produção de uma nova realidade. "O gênero humano transforma e se transforma a si mesmo e essa história de suas transformações é propriamente sua verdadeira história” (SANCHEZ VÁZQUEZ, 2011, p. 341). Na escola, o pedagógico torna-se um significativo elemento desencadeador das transformações dos sujeitos. Nesse aspecto reside a importância de compreender como as intencionalidades que permeiam as relações ocorridas no espaço escolar, assim como o caráter pedagógico que se manifesta entre os sujeitos Reforçamos novamente, que na perspectiva do "trabalho pedagógico" (FERREIRA 2008, 2017, 2018), é cara a relação dos professores com a produção do conhecimento, com os alunos e a escola.

$\mathrm{Na}$ abordagem em estudo, a matéria-prima da práxis é o pedagógico, o qual estabelece vínculos com o trabalho de professores e o trabalho pedagógico, categorias desenvolvidas no decorrer desse artigo. A associação entre as categorias mencionadas possibilita que se criem mecanismos na escola, para a superação das condições impostas pelo modo de produção capitalista e a criação de espaços para a práxis. Os professores produzem aula não como sujeitos individuais, pois na essência dessa produção, estão presentes os sentidos destes profissionais como grupo de trabalhadores. Da mesma forma, o pedagógico desses professores está tomado pelos mesmos sentidos, que vão do individual ao coletivo e institucional.

Nessa perspectiva, consideramos a relevância do estudo do trabalho de professores, porém, defendemos o "trabalho pedagógico", pois envolve compreender as condições, as dimensões, o espaço e o tempo em que estes sujeitos se autoproduzem e por meio da interlocução, se produzem na convivência com os estudantes.

\subsection{A ANÁLISE QUE FIZEMOS DOS TEXTOS SELECIONADOS}

Como já explicitamos, o intuito da análise é um estudo dos movimentos de sentidos das categorias em revistas que, naquele momento, tinham o qualis ${ }^{9} \mathrm{~A}$ na área de Educação Física, ou seja, teriam sido submetidas a critérios de análise quanto à, por exemplo, periodicidade, diversidade e distinção dos artigos publicados, para obter esta distinção. Tal critério visava a estabelecer mais um parâmetro de aproximação nas características entre as revistas: ambas eram da mesma área do conhecimento e distinguiam-se por sua posição na tabela qualis da CAPES, no momento da pesquisa. Na etapa de categorização, como já relatado, chegou-se a sete textos para análise. Os textos foram relidos e, neles, foram demarcadas as abordagens das categorias. São essas abordagens que passaremos analisar.

a) Trabalho pedagógico é tratado, de modo genérico, integrado a outros elementos. Vejamos como esses movimentos de sentidos acontecem: trabalho pedagógico é incluído na relação com currículo, com condições de trabalho, porém não é descrito, como no exemplo: "[...] as características dos professores baseiam-se nos conhecimentos sobre os assuntos abordados em sala de aula, avaliação da qualidade do trabalho pedagógico, bem como da disponibilidade de recursos e de condições para o trabalho" (BOTH; NASCIMENTO, 2009, p. 171). A relação com o currículo é assentada no pressuposto que determina mudanças no trabalho

9 Ao longo do período compreendido na análise dos artigos, ambos periódicos estiveram avaliados com Qualis A. Atualmente - tendo como referência o ano de publicação deste estudo - a Motriz está avaliada com Qualis B1. 
pedagógico. No caso, por exemplo, dos ciclos de formação, acontecem uma série de alterações institucionais, que incluem "metodologias e procedimentos de ensino, mas mexem, especialmente, com os princípios e pressupostos educacionais daqueles que integram o sistema escolar" (PEREIRA; MENDES, 2010, p. 110). É nesse espaço, segundo os autores, que o trabalho pedagógico se altera para se adequar aos novos objetivos. E, mais adiante, reiteram "O trabalho pedagógico possui uma dimensão política, na medida em que poderá auxiliar ou inibir a relação cognitiva entre as expressões culturais dos alunos e os conteúdos da disciplina" (PEREIRA; MENDES, 2010, p. 123). Trabalho pedagógico, também, é incluído na categoria "organização do trabalho pedagógico". Esta categoria, na Pedagogia, não tem o mesmo impacto que teve na Educação Física. Na Pedagogia, opta-se por falar-se em didática em vez de organização do trabalho pedagógico. Com argumentação contrária à nossa, Freitas (1994 p. 88), explica que a didática é uma expressão que deve ser subsumida ao de Organização do Trabalho Pedagógico entendendo-se, este último em "[...] dois níveis: a) como trabalho pedagógico que, [...], costuma desenvolver-se predominantemente em sala de aula; e b) como organização global do trabalho pedagógico na escola, enquanto projeto político-pedagógico da escola".

Em um ensaio, os autores demonstram a compreensão que possuem do trabalho pedagógico ao afirmarem que este é todo trabalho realizado pelo professor na escola em uma visão mais ampla, "considerando também as articulações entre estruturas sociais, políticas, econômicas e a realidade da docência na escola" (DALLA NORA et al., 2016, p. 1367). Deste modo, é uma prática social e, assim sendo, é influenciado pelas relações sociais, repercutindo no trabalho que é desenvolvido pelo professor.

Interessante observar que, em um dos artigos, prática é vista como dissociada da organização do trabalho pedagógico. Segundo os autores, determinados segmentos da comunidade escolar e acadêmica percebiam o professor como um profissional voltado eminentemente para a prática, apresentando lacunas na sua formação quando analisa sob a perspectiva da sua inserção na organização do trabalho pedagógico (PEREIRA; MENDES, 2010, p. 127).

b) Trabalho docente é categoria mais abordada que as demais, denotando ser uma expressão mais recorrente na literatura pedagógica para descrever o trabalho dos professores. Pereira e Mendes (2010, p. 127), com base em Freire (2002) e Molina Neto (1998; 2003), caracterizam trabalho docente como: "[...] espaço não apenas de mobilização, mas também de produção de saberes, rompendo, assim, com a perspectiva do professor apenas como transmissor de conhecimentos e mostrando que ele pode ser também produtor e articulador das situações reais produzidas nas relações estabelecidas pelos alunos nos meios em que se inserem" (Pereira; Mendes, 2010, p. 116).

Pereira e Mendes (2010) partem da base de Freire (2002) e Molina Neto (1998; 2003) para afirmarem que na especificidade da Educação Física, o trabalho definido por elas como docente requer a garantia do princípio da coletividade na organização do componente curricular. Com base em Freire e Nogueira (2007) afirmam que o trabalho docente: 
[...] possui uma dimensão política na qual o professor é um profissional ativo. Nessa perspectiva, o professor que questiona a maneira como poderá trabalhar melhor os interesses e as peculiaridades dos alunos das periferias está colocando em dúvida o ensino e a escola que aí estão (PEREIRA; MENDES, 2010, p. 122).

Encontramos também denúncia de que o trabalho docente se encontra prejudicado em meio às condições em que é realizado, entretanto, não se nega, a partir das considerações de Marin, Souza, Ribas, Decian e Herbst (2011), que a rotina deste trabalho não possa produzir práticas cristalizadas, fundamentadas em modelos pré-determinados.

Outra denúncia aparece em artigo que trata de qualidade de vida:

O constitucionalismo na organização do trabalho, com foco nos direitos e deveres do professor na escola; o trabalho e espaço total de vida, que retrata o equilíbrio entre o tempo dedicado ao trabalho com o tempo dedicado ao lazer; e a relevância social da vida no trabalho, que aborda como a instituição procura incutir no professor a relevância social de sua atividade são componentes da qualidade de vida no trabalho docente (MOREIRA; NASCIMENTO; SONOO; BOTH, 2010, p. 907).

Como alternativa, um grupo de autores defende que a hermenêutica pode se constituir em potencial modo de os professores realizarem seu trabalho, na medida em que possibilita o que consideram fundamental: a interpretação do entorno do trabalho docente (REZER; FENSTENSEIFER; NASCIMENTO, 2011). Apontam os autores que este trabalho exige esforço de interpretação de conhecimentos que não foram desenvolvidos inicialmente para o campo de atuação do professor. "Isso significa que a hermenêutica se faz presente em diferentes momentos do trabalho docente, desde o recorte do conteúdo, até as escolhas sobre a forma de trabalhar determinado assunto, etc" (2011, p. 130).

Uma complementar alternativa é apresentada em outro artigo, de autoria de Gomes, Chagas e Mascarenhas (2010), na qual se encontra uma associação entre trabalho docente e trabalho pedagógico. Entendem estes que a docência é compreendida como um ofício constituído de saberes construídos e reconstruídos no exercício da profissão e, neste sentido, o afastamento do professor das suas funções (conceber, planejar e avaliar sua prática pedagógica) resulta em uma docência esvaziada de sentido e significados, vindo a impor "fortes limites a sua autonomia, isto é, a sua capacidade de diagnosticar contextos para exercer, com competência técnica e política, o trabalho pedagógico para com as práticas corporais, neste particular, a ginástica" (GOMES, CHAGAS, MASCARENHAS, 2010, p. 185).

Ao analisarmos o texto de Rufino (2017), encontramos o entendimento de que o trabalho docente pode ser compreendido como uma construção social contingente e oriunda das atividades realizadas pelos professores no exercício de suas ações na escola. Conforme entende este autor, os professores desempenham suas ações profissionais tendo uma próxima relação com os estudantes e demais agentes do processo educativo.

Percebe-se que, de modo geral, os textos não distinguem as categorias de análise, transformando-as em sinônimos. Entretanto, pensamos que são categorias 
atinentes a processos diferenciados que, resumidamente, a partir do que defendemos anteriormente, não se substituem, se complementam em argumentações que têm bases teóricas diferenciadas.

Conforme proposto no início do artigo, objetivamos analisar as categorias "trabalho docente", "trabalho de professores" e "trabalho pedagógico", nas produções pesquisadas, sustentando nossa opção em abordar as questões intervenientes na escola, e no trabalho que nela se constitui, a partir do viés que ressalta o pedagógico e o trabalho que se organiza a partir da sua orientação.

\section{CONSIDERAÇÕES FINAIS}

A análise dos textos revelou alguns aspectos que consideramos importante nesse garimpo de sentidos para categorias que têm sido caras para os estudos que realizamos: trabalho pedagógico, trabalho dos professores e trabalho docente. Tais aspectos podem nos possibilitar estabelecer renovados objetivos nos rumos de nossas pesquisas. Sistematizamos os aspectos encontrados da seguinte forma:

a) Há, ainda, uma tendência em aplicar trabalho docente, trabalho pedagógico e trabalho dos professores como expressões que sejam sinônimos, e que possam se substituir em termos de sentidos;

b) Trabalho docente é a expressão mais aplicada para referir-se ao trabalho dos professores. Entretanto, no modo como é descrita, parece não revelar o que entendemos ser fundamental: o contexto, as condições, os discursos, os imaginários desse trabalho em escolas com marcadas características capitalistas;

c) Organização do trabalho pedagógico é uma expressão aplicada em sentido mais ampliado que trabalho pedagógico. Entretanto, por se apresentar sobreposta à didática, parece ficar descolada de um aspecto fundamental: de toda uma tradição de estudos da Pedagogia, os quais remetem a se pensar mais amplamente o fenômeno educacional. Desse modo, organização do trabalho pedagógico parece se reportar à dimensão de "prática" pedagógica, o instantâneo, o imediato.

d) A análise remeteu à percepção do valor do trabalho pedagógico como categoria de estudo. Conforme argumentamos, existem múltiplos vieses para a definição do trabalho no âmbito da educação e neste campo, optamos por nos aproximarmos das articulações entre trabalho e pedagógico, encaminhados para uma transformação da realidade pautada em elementos que se relacionam dialeticamente no contexto da luta de classes, em que se produzem sujeitos.

e) No período em análise, o trabalho, seja docente, dos professores ou pedagógico, não foi categoria recorrente nas produções acadêmicas analisadas. Ressaltamos a necessidade de publicações que enfatizem o trabalho que acontece na escola, seus enfrentamentos com os mecanismos de controle do capital, entre outros. É significativo que estas publicações se proliferem, para que circulem ideias e se amplie o debate sobre o trabalho no âmbito da Educação Física.

Evidentemente, esse é um estudo inicial e necessita ser continuado visando ao aprofundamento sempre em contínuo. Comparativamente, pode-se ir, ao mesmo 
tempo, apreendendo outros significados das categorias em análise bem como avaliando o que temos produzido.

\section{REFERÊNCIAS}

ANDRADE, Rafael Júnio; PEREIRA, Eveline Torres; BOTELHO, Maria Izabel Vieira Botelha; SILVA, Sílvio Ricardo. Trabalho destruído e funcionalização do lazer: possíveis relações em tempos de alta modernidade. Movimento, v. 14, n. 1, p.163 - 185, 2008. Disponível: http:// seer.ufrgs.br/Movimento/article/view/3763. Acesso em: 20 ago. 2019.

BOSSLE, Fabiano; MOLINA NETO, Vicente. Leituras para (Re)Pensar o Trabalho Coletivo dos Professores de Educação Física. Movimento, v. 15, n. 3. p. 89 - 107, 2009. Disponível em: http://seer.ufrgs.br/Movimento/article/view/6877. Acesso em: 20 ago. 2019.

BOTH, Jorge; NASCIMENTO, Juarez Vieira. Intervenção profissional na educação física escolar: considerações sobre o trabalho docente. Movimento, v. 15, n. 2. p. 169 - 186. 2009. Disponível em: http://seer.ufrgs.br/Movimento/article/view/3046. Acesso em: 20 ago. 2019.

CALHEIROS, Vicente Cabrera; SOUZA, Maristela da Silva. A educação do MST e a relação com o Estado: análise a partir da avaliação em Educação Física na Escola Nova Sociedade. Movimento, v. 21, n. 2, p. 533-544, abr./jun. 2015.

DALLA NORA, Daiane; WELTER, Janaíne; WELTER, Jaqueline; BUFFON, Elciana; RIBAS, João Francisco Magno. Praxiologia motriz, trabalho pedagógico e didática na Educação Física. Movimento, v. 22, n. 4, out./dez. 2016. DOI: https://doi.org/10.22456/1982$\underline{8918.65268}$

FERREIRA, Liliana Soares. Gestão do pedagógico: de qual pedagógico se fala? Currículo sem Fronteiras, v. 8, n. 2, p. 176-189, 2008.

FERREIRA, Liliana Soares. Trabalho pedagógico na escola: sujeitos, conhecimentos e tempo. Curitiba: CRV, 2017.

FERREIRA, Liliana Soares. Trabalho Pedagógico na Escola: do que se fala? Educação e Realidade. v. 43, n. 2, p. 591-608, 2018.

FERREIRA, Liliana Soares; BRAIDO, L. S; DE TONI, D. L. P. "Pedagogia nas Produções Acadêmicas da Pós-Graduação em Educação no RS: Análise dos Movimentos de Sentidos". Cocar UEPA, Ed. Esp., n.8. p. 146- 164, jan./abr. 2020.

FERREIRA, Liliana Soares; RIBAS, João Francisco Magno. "Trabalho dos professores como práxis pedagógica”. Movimento, v. 20, n. 1, p. 125-143, jan./mar. 2014.

FREIRE, Paulo. Pedagogia da autonomia. Saberes necessários à prática educativa. São Paulo: Paz e Terra, 2002.

FREIRE, Paulo. Pedagogia do Oprimido. 26. ed. Rio de Janeiro: Paz e Terra, 1987.

FREIRE, Paulo; NOGUEIRA, Adriano. Que fazer: teoria e prática em educação popular. 9. ed. Petrópolis/RJ: Vozes, 2007.

FREITAS, Luiz Carlos de. Crítica da organização do trabalho pedagógico e da didática. 1994. (Tese de Doutorado) - Faculdade de Educação da Universidade Estadual de Campinas, Campinas, 1994. 
FRIZZO, Giovanni Ernest Felipo. Trabalho pedagógico: conceito central no trato do conhecimento da pesquisa em educação. Trabalho Necessário, v. 6, n. 6. p. 1- 29, 2008.

GOMES, Ingrid Rodrigues; CHAGAS, Regiane de Avila; MASCARENHAS, Fernando. A indústria do fitness, a mercantilização das práticas corporais e o trabalho do professor de Educação Física: o caso Body Systems. Movimento, v. 16, n. 4. p. 169 - 189, 2010. Disponível em: http://seer.ufrgs.br/Movimento/article/view/14561. Acesso em: 20 ago. 2019.

HARGREAVES, Andy. Os professores em tempos de mudança: o trabalho e a cultura dos professores na idade pós-moderna. Portugal: MacGraw Hill, 1998.

KUENZER, Acácia Zenaide. Exclusão includente e inclusão excludente: A nova forma de dualidade estrutural que objetiva as novas relações entre educação e trabalho. In: LOMBARDI, José Claudinei; SAVIANI, Dermeval; SANFELICE, José Luis (orgs). Capitalismo, Trabalho e Educação. 2. ed., Campinas, SP: Autores Associados, 2002. p.77-96.

LIBÂNEO, José Carlos. Pedagogia e pedagogos, para quê?. São Paulo, Cortez, 1998.

MACHADO, IIma Ferreira. A organização do trabalho pedagógico em uma escola do MST e a perspectiva de formação omnilateral. 2003. (Tese de doutorado) - Faculdade de Educação da Universidade Estadual de Campinas, Campinas, 2003.

MARIN, Elizara Carolina; SOUZA, Maristela da Silva; RIBAS, João Francisco Magno; DECIAN, Marluce Raquel; HERBST, Fabiano Rossato. Formação continuada em Educação Física: relação entre mundo do trabalho, políticas educacionais e educação. Movimento, v. 17, n. 2, p. 259 - 278, 2011. Disponível em: http://seer.ufrgs.br/Movimento/article/ view/16670. Acesso em: 20 ago 2019.

MARQUES, Mário Osório. Educação nas ciências: novos desafios. Educação nas Ciências - Revista do Programa de Pós-Graduação em Educação nas Ciências, UNIJUI, ano 1, n. 1, p. 21-46, jan./jun. 2001.

MARQUES, Mário Osório. Educação / interlocução, aprendizagem / reconstrução de saberes. ljuí: Editora UNIJUÍ, 1996.

MARX, Karl. O capital: crítica da economia política: Livro l: o processo de produção. São Paulo: Boitempo, 2013.

MOLINA NETO, Vicente. Crenças do professorado de Educação Física das escolas públicas de Porto Alegre - RS/Brasil. Movimento, v. 9, n. 1. p. 145-169, 2003.

MOLINA NETO, Vicente. A prática dos professores de Educação Física das escolas públicas de Porto Alegre. Movimento, v. 5, n. 9, p. 31-46, 1998.

MOREIRA, Hudson de Resende; NASCIMENTO, Juarez Vieira do; SONOO, Christi Noriko; BOTH, Jorge. Qualidade de vida no trabalho e perfil do estilo de vida individual de professores de Educação Física ao longo da carreira docente. Motriz, v. 16, n. 4, 2010. Doi: http://dx.doi.org/10.5016/1980-6574.2010v16n4p900

NASCIMENTO, Raquel; MARTINS, Alessandra Catarina; BOTH, Jorge; FARIAS, Gelcemar Oliveira; GUIMARÃES, Juliana Regina; FOLLE. Alexandra. Satisfação no trabalho de docentes de Educação Física: uma revisão sistemática. Movimento, v. 25, jan./dez. 2019. Disponível em: https://seer.ufrgs.br/Movimento/article/view/82573. Acesso em: 20 maio 2020.

NUNES, Marcello Pereira; VOTRE, Sebastião Josué; SANTOS, Wagner. O profissional em Educação Física no Brasil: desafios e perspectivas no mundo do trabalho. Motriz, v. 18, n. 2. p. 280 - 290, 2012. Disponível em: http://www.periodicos.rc.biblioteca.unesp.br/index.php/ motriz/article/view/4975. Acesso em: 20 ago. 2019. 
PEREIRA, Neiva; MENDES, Valdelaine. A Educação Física na escola organizada por ciclos de formação: especificidades do trabalho docente. Movimento, v. 16, n. 03, p. 109-132, jul./set. 2010.

PRONI, Marcelo Weishaupt. Universidade, profissão Educação Física e o mercado de trabalho. Motriz, v. 16, n. 3. p. 788 - 798, 2010. Disponível em: http://dx.doi. org/10.5016/1980-6574.2010v16n3p788. Acesso em: 20 ago. 2019.

REZER, Ricardo; FENSTERSEIFER, Paulo Evaldo; NASCIMENTO, Juarez Vieira. Aproximações com a hermenêutica: um referencial para o trabalho docente no campo da Educação Física. Movimento, v. 17, n. 2, abr./jun. 2011. DOI: https://doi.org/10.22456/1982$\underline{8918.19358}$

RIBAS, João Francisco Magno; FERREIRA, Liliana Soares. Trabalho de professores na escola como práxis pedagógica. Movimento, v. 20, n. 01, p. 125-143, jan./mar. 2014.

RUFINO, Luiz Gustavo Bonatto. O trabalho docente na perspectiva de professores de Educação Física: análise de alguns fatores condicionantes e suas restrições para o desenvolvimento da prática pedagógica. Movimento, v. 23, n. 4, out./dez. 2017. DOI: https:// doi.org/10.22456/1982-8918.66771

SÁNCHEZ VÁZQUÉZ, Adolfo. Filosofia da práxis. 2. ed. São Paulo: Expressão Popular, 2011.

SHIROMA, Eneida Oto. O eufemismo da profissionalização. In: MORAES, Maria Célia Marcondes (org.). lluminismo às avessas: produção de conhecimento e políticas de formação docente. Rio de Janeiro: DP\&A, 2003. p. 61 - 79.

TANI, Go. Preparação profissional em Educação Física: mudando mercado de trabalho e competência. Motriz, v. 19, n. 03, p. 552 - 557, 2013. Disponível em: http://www.periodicos. rc.biblioteca.unesp.br/index.php/motriz/article/view/7367. Acesso em: 20 ago. 2019.

VERENGER, Rita Cassia Garcia; CAMPANELLI, José Renato; KALLAS, Daniele; FREIRE, Elisabete dos Santos; COSTA, Ferdinand Camara da. Mercado de trabalho em EF: o significado da intervenção profissional em academias de ginástica. Motriz, v. 14, n. 4. p. 452 - 461, 2008. Disponível em: http://www.periodicos.rc.biblioteca.unesp.br/index.php/motriz/ article/view/2133. Acesso em: 20 ago. 2019.

VILLAS BOAS, Benigna Maria de Freitas As práticas avaliativas e a organização do trabalho pedagógico. 1993. Tese (Doutorado em Educação) - Faculdade de Educação da Universidade Estadual de Campinas, Campinas, 1993.

VOTRE, Sebastião José; VIGNE, Joana Angélica; LACERDA, Yara. Mulheres da rocinha: relações entre corpo, identidade e trabalho. Movimento, v. 14, n. 3. p. 53 - 69, 2008.

Disponível em: http://seer.ufrgs.br/Movimento/article/view/2550. Acesso em: 20 ago. 2013.

WITTIZORECKI, Elisandro Schultz; MOLINA NETO, Vicente. BOSSLE, Fabiano. Mudanças sociais e o trabalho docente de professores de Educação Física na escola: estudo a partir de histórias de vida. Movimento, v. 18, n. 1. p. 149 - 169, 2012. Disponível em: http://seer. ufrgs.br/Movimento/article/view/23894. Acesso em: 20 ago. 2013.

\section{Apoio:}

Conselho Nacional de Desenvolvimento Científico e Tecnológico - CNPq (Processo 303650/2016-8) e da Fundação de Apoio à Pesquisa no Estado do Rio Grande do Sul - FAPERGS e Coordenação de Aperfeiçoamento de Pessoal de Nível Superior -Brasil (CAPES) (Processo 18/2551-0000550-9). 